\title{
Number needed to treat and number needed to harm with paliperidone palmitate relative to long-acting haloperidol, bromperidol, and fluphenazine decanoate for treatment of patients with schizophrenia
}

This article was published in the following Dove Press journal:

Neuropsychiatric Disease and Treatment

4 March 201I

Number of times this article has been viewed

\section{Srihari Gopal' \\ Joris Berwaerts' \\ Isaac Nuamah' \\ Kasem Akhras ${ }^{2}$ \\ Danielle Coppola' \\ Ella Daly' \\ David Hough' \\ Joseph Palumbo'}

'Johnson \& Johnson Pharmaceutical Research \& Development, LLC. Raritan, NJ, USA; ${ }^{2}$ Johnson \& Johnson Pharmaceutical Services, LLC, Raritan, NJ, USA
Correspondence: Srihari Gopal Johnson \& Johnson Pharmaceutical Research \& Development,

II 25 Trenton Harbourton Road,

Titusville, NJ 08560, USA

$\mathrm{Tel}+\mathrm{I} 6097302000$

Fax + I 6097302323

Email SGopal2@its.jnj.com
Background: We analyzed data retrieved through a PubMed search of randomized, placebocontrolled trials of first-generation antipsychotic long-acting injectables (haloperidol decanoate, bromperidol decanoate, and fluphenazine decanoate), and a company database of paliperidone palmitate, to compare the benefit-risk ratio in patients with schizophrenia.

Methods: From the eight studies that met our selection criteria, two efficacy and six safety parameters were selected for calculation of number needed to treat (NNT), number needed to harm $(\mathrm{NNH})$, and the likelihood of being helped or harmed ( $\mathrm{LHH})$ using comparisons of active drug relative to placebo. NNTs for prevention of relapse ranged from 2 to 5 for paliperidone palmitate, haloperidol decanoate, and fluphenazine decanoate, indicating a moderate to large effect size.

Results: Among the selected maintenance studies, NNH varied considerably, but indicated a lower likelihood of encountering extrapyramidal side effects, such as akathisia, tremor, and tardive dyskinesia, with paliperidone palmitate versus placebo than with first-generation antipsychotic depot agents versus placebo. This was further supported by an overall higher $\mathrm{NNH}$ for paliperidone palmitate versus placebo with respect to anticholinergic use and Abnormal Involuntary Movement Scale positive score. LHH for preventing relapse versus use of anticholinergics was 15 for paliperidone palmitate and 3 for fluphenazine decanoate, favoring paliperidone palmitate.

Conclusion: Overall, paliperidone palmitate had a similar NNT and a more favorable NNH compared with the first-generation long-acting injectables assessed.

Keywords: long-acting injectables, first-generation antipsychotics, randomized, number needed to treat, number needed to harm, paliperidone palmitate, second-generation antipsychotics

\section{Introduction}

Long-acting injectable preparations of both first- and second-generation antipsychotics offer certain advantages over oral preparations, such as a longer interval between dosing, the opportunity for the health care provider to intervene if an injection is missed, mitigation against the nonadherence or partial adherence that is prevalent with oral agents, and the ability to maintain efficacy with improved tolerability, as a result of less peak-to-trough fluctuation in plasma concentration. ${ }^{1,2}$ However, the incidence of extrapyramidal symptoms and other movement disorders, such as tardive dyskinesia, 
has been reported to be considerable with first-generation antipsychotic long-acting injectables. ${ }^{3}$

By comparison, use of second-generation oral and longacting injectable antipsychotics have been generally associated with a reduced risk of developing tardive dyskinesia and treatment-limiting extrapyramidal symptoms. ${ }^{4,5}$ However, there are no randomized controlled trials directly comparing the efficacy, safety, and tolerability of first- and second-generation long-acting injectables in patients with schizophrenia. In the absence of head-to-head comparisons in clinical studies, standardized measures of benefit and risk allow practicing clinicians to compare clinically discernable treatment effects and assess their significance across clinical trials. ${ }^{6}$

The number needed to treat (NNT), number needed to harm (NNH), and likelihood of being helped or harmed (LHH) are evidence-based tools that provide information on the relative risk or benefit of various treatments. ${ }^{7,8}$ These measures are based on a calculation of the number of patients who will likely need to be treated with the test agent to either benefit a single patient (NNT) or cause a single patient to experience harm $(\mathrm{NNH})$ relative to treatment with the reference agent (eg, placebo). LHH is the ratio of the absolute risk reduction for prevention of an adverse outcome (1/NNT) versus an absolute risk increase for safety $(1 / \mathrm{NNH}),{ }^{9}$ and allows physicians to compare treatments across studies and individualize treatment decisions for patients with a distinct set of risk factors. ${ }^{9}$ Thus, NNT, NNH, and $\mathrm{LHH}$ provide easily translatable information to the health care provider and patients. ${ }^{10,11}$

Here, we report the NNT, NNH, and LHH for selected efficacy and safety parameters from randomized, placebo-controlled studies of paliperidone palmitate, a second-generation longacting injectable antipsychotic, and haloperidol decanoate, fluphenazine decanoate, and bromperidol decanoate, three first-generation long-acting injectable antipsychotics used in patients with schizophrenia. Bromperidol decanoate is an older depot neuroleptic used in several European countries. The primary objective of this analysis was to compare the efficacy and safety of paliperidone palmitate with that of firstgeneration long-acting injectable antipsychotics by calculating and comparing NNT and NNH based on available data from the published literature.

\section{Methods}

\section{Search criteria}

A computerized search of medical literature databases was conducted in September 2009 using PubMed (www.pubmed.gov) and an internal company product-related database of published abstracts, posters, and articles. The literature search was restricted to randomized, controlled studies (of any duration, in any language, retrievable through PubMed) of known first-generation long-acting injectable antipsychotics.

During the PubMed search, the following search terms (medical subject headings [MeSH] or verbatim) were used to encompass all known first-generation long-acting injectable antipsychotics, ie, fluphenazine decanoate, haloperidol decanoate, bromperidol decanoate, clopenthixol decanoate, flupenthixol decanoate, pipothiazine palmitate, fluspirilene, and perphenazine enanthate. For these MeSH terms, the field tags were limited to "title or abstract". In addition, "type of article" was limited to "randomized controlled trial", "human" was selected for "species", the "age" criterion was "all adults 19+ years", and articles in "all languages". A total of 15 randomized, controlled clinical trials evaluating the efficacy and safety of first-generation long-acting injectables were retrieved. One of these retrieved articles was written in a non-English language. ${ }^{12}$ An English version of the abstract and the Italian version of the full manuscript were available, the results of which were interpreted by a native speaker. No articles meeting the selection criteria above were found for the following, and hence were excluded from further analysis: clopenthixol decanoate, flupenthixol decanoate, pipothiazine palmitate, fluspirilene, and perphenazine enanthate. No placebocontrolled relapse prevention studies for long-acting injectable olanzapine and long-acting injectable risperidone were found in the literature search. Additionally, the search did not retrieve any studies of first-generation long-acting injectable antipsychotics for the acute treatment of patients with schizophrenia. A search of published Cochrane reviews also did not provide additional studies meeting the inclusion criteria. ${ }^{13-15}$

For paliperidone palmitate, a search within the internal company database ("literature management and documentation") was performed using the search terms, "double-blind", "randomized", "human", and "intramuscular", with the indication "schizophrenia". The internal database contains all published abstracts, posters, and manuscripts for company products and is not publicly accessible, although many of the documents may be found through other external searches. Four studies of acute treatment and one of maintenance treatment for schizophrenia were identified.

\section{Selected studies}

We then narrowed the selected studies to those that included a placebo control, because comparisons between treatments using NNT and NNH calculations require a common 
comparator, eg, placebo. A common comparator is necessary to allow for characterization of the efficacy and safety of the treatments of interest with reference to the same comparator across studies. These types of comparisons are indirect in nature and distinct from observations in a randomized controlled trial that include direct head-to-head comparisons of the treatments of interest. Furthermore, because calculations of NNT and NNH require binary endpoints, we included only those publications that had clinical outcomes of interest with binary endpoints that were common among at least two of the published studies, and provided enough details to be able to assess them. Studies with continuous variables for efficacy and safety measures that could not be converted to binary endpoints were not included. Accordingly, of the 16 retrieved studies for maintenance treatment, only seven (six for firstgeneration long-acting injectables, and one for paliperidone palmitate) fully met the inclusion criteria of being placebocontrolled and having binary endpoints for clinical outcomes of interest. Of these, six studies had time to relapse or relapse rate as a clinical efficacy endpoint. ${ }^{12,16,18-21}$ The only study retrieved for bromperidol decanoate did not assess efficacy using time to relapse or relapse rate, and hence was included only for safety evaluations using $\mathrm{NNH}^{22}$

Of the four acute treatment studies with paliperidone palmitate that were initially identified, three used a lower dose-loading regimen than that currently approved by the US Food and Drug Administration, so were excluded, ${ }^{23-25}$ leaving one acute treatment study for the main analysis. ${ }^{17}$ These three studies utilized an older dosing regimen that led to considerably lower initial plasma concentrations of paliperidone. A subsequent sensitivity analysis including

Table I Sensitivity analysis for number needed to harm and number needed to treat for acute symptom studies for paliperidone palmitate that used an earlier initiation regimen

\begin{tabular}{|c|c|c|c|}
\hline $\begin{array}{l}\text { Clinical outcome } \\
\text { NNT or NNH } \\
(95 \% \mathrm{Cl})\end{array}$ & $\begin{array}{l}{ }^{\text {a Gopal }} \\
\text { et } \mathbf{a l}^{25}\end{array}$ & $\begin{array}{l}\text { bNasrallah } \\
\text { et } \mathrm{al}^{24}\end{array}$ & $\begin{array}{l}\text { 'Kramer } \\
\text { et } \mathrm{al}^{23}\end{array}$ \\
\hline Response & $9(5,64)$ & $8(5,26)$ & $5(4,12)$ \\
\hline Akathisia & $78(24,-37)$ & $-322(46,-21)$ & $-87(42,-15)$ \\
\hline Tremor & $-210(29,-18)$ & $100(34,-38)$ & $-57(65,-14)$ \\
\hline Tardive dyskinesia & $252(46,-42)$ & $\infty$ & $\infty$ \\
\hline $\begin{array}{l}\text { Use of } \\
\text { anticholinergics }\end{array}$ & $33(10,-20)$ & $-8 \mid(27,-13)$ & $12(7,545)$ \\
\hline $\begin{array}{l}\text { AIMS positive } \\
\text { score }\end{array}$ & $22(8,-22)$ & $-108(16,-11)$ & $-37(13,-7)$ \\
\hline Weight gain & $36(18,-299)$ & $28(17,3 \mid 3)$ & $2739(31,-19)$ \\
\hline
\end{tabular}

Notes: $\infty$ indicates confidence interval includes infinity; initial dose on days I and 8: a50, 100, $150 \mathrm{mg}$ eq; ' $25,50,100 \mathrm{mg}$ eq; ${ }^{5} 50,100 \mathrm{mg}$ eq.

Abbreviations: AIMS, Abnormal Involuntary Movement Scale; NNT, number needed to treat; $\mathrm{NNH}$, number needed to harm; $\mathrm{Cl}$, confidence interval. these three studies with alternative dosing regimens was conducted and yielded similar results (Table 1).

\section{Selection of efficacy and safety endpoints for comparison}

From the identified studies, as expected, not all outcomes were reported uniformly in the published manuscripts. Thus, prevention of relapse was compared between paliperidone palmitate, fluphenazine decanoate, and haloperidol decanoate (the only bromperidol decanoate study included did not assess prevention of relapse). The NNT for response to treatment was calculated from the Pandina et $\mathrm{al}^{17}$ study for paliperidone palmitate. Thus, the efficacy parameters chosen were "response" (based upon $\geq 30 \%$ reduction in the Positive and Negative Symptoms Scale [PANSS] total score from baseline at the last postbaseline assessment) in the acute treatment study ${ }^{17}$ and "relapse" (as derived from data on "time to relapse" or "relapse rate") in the maintenance treatment studies. ${ }^{12,16,18-21}$

The six safety parameters chosen across the studies were: (1) incidences of reported adverse event rates of akathisia, tremor, tardive dyskinesia, or weight gain, as well as (2) the proportion of patients who used anticholinergic medications (which is an indirect measure of clinically relevant extrapyramidal symptomrelated effects, and the proportion of patients who had emergence of a "positive" Abnormal Involuntary Movement Scale (AIMS) total score as reported in each of the publications. Accordingly, the incidence of tardive dyskinesia was compared between paliperidone palmitate, fluphenazine decanoate, and haloperidol decanoate. Incidences of anticholinergic medication use, and AIMS positive score were compared between paliperidone palmitate and fluphenazine decanoate, and treatment-emergent tremor, akathisia, and weight gain were compared between paliperidone palmitate and bromperidol decanoate.

\section{Calculation of NNT, NNH, and LHH}

NNT and NNH were calculated as the reciprocal of the absolute difference in event rates (Table 2). LHH was calculated based on the method described by Straus. ${ }^{9}$ Survival studies with an

Table 2 Formulae used to calculate number needed to treat, number needed to harm, and likelihood of being helped or harmed

\begin{tabular}{ll}
\hline Measure of effect & Formula \\
\hline NNT & $I / A R R=I / S_{t}-S_{c}$ \\
NNH & $I / A R I=I / S_{t}-S_{c}$ \\
LHH & ARR/ARI $=N N H / N N T$ \\
\hline
\end{tabular}

Abbreviations: $A R R$, absolute risk reduction; $A R I$, absolute risk increase; $S$, event rate in treatment group; $S_{c}$, event rate in control group; NNT, number needed to treat; $\mathrm{NNH}$, number needed to harm; $\mathrm{LHH}$, likelihood of being helped or harmed. 
endpoint of time to relapse require an estimate of the survival probability at fixed time points to support calculation of NNT. Because older studies lacked information on the corresponding survival probability, hazard ratio or number at risk were used. For comparison, we calculated the confidence interval (CI) for NNT at distinct time points (6 and 12 months) for the paliperidone palmitate study. The CIs of NNT to prevent relapse in other studies with various fixed durations (6-48 months) were calculated according to the method described by Altman and Andersen. ${ }^{26} \mathrm{CIs}$ for NNT for treatment response (ie, $\geq 30 \%$ reduction from baseline in PANSS total score) and CI of NNH for the selected safety measures were constructed using the Wilson score method using a program written in SAS 9.1 (SAS Institute Inc, Cary, NC). ${ }^{27-29}$

All comparisons performed in this analysis were conducted by comparing the event rate in the medication-ofinterest group with the placebo group event rate in the selected studies. Negative values for NNT or NNH imply that the treatment of interest is more likely to result in harm than benefit. For example, a negative NNT in this analysis indicates that a patient assigned to the medication of interest is more likely to experience relapse than a patient assigned to placebo. Similarly, a negative NNH indicates that a patient assigned to placebo has a lower risk for the adverse event than a patient assigned to the medication of interest. Infinity values for NNT or NNH indicate that an infinite number of patients would be required to show any benefit or harm. If the $95 \%$ CI for NNT or NNH includes infinity, the finding is considered statistically nonsignificant.

\section{Results}

\section{Study characteristics}

Across the selected maintenance studies of first-generation long-acting injectables and paliperidone palmitate, the patient stabilization period before randomization, if applicable, varied between two months and two years. Additionally, the follow-up time varied significantly between the studies (range 6-48 months), and the relapse rates varied across the placebo-treated groups (range 30\%-71\%).

Across the selected randomized controlled survival studies, the crude relapse rates in the long-acting injectabletreated groups were similar (range 10\%-19\%, Table 3). The NNT to prevent relapse relative to placebo ranged between two and five for paliperidone palmitate, fluphenazine decanoate, and haloperidol decanoate (Table 4 and Figure 1). NNT for clinical response reflected the established efficacy of paliperidone palmitate relative to placebo for the primary efficacy measure (ie, change from baseline in PANSS total score, Table 4). For bromperidol decanoate, no relevant efficacy data were available to calculate an NNT.

Across the selected maintenance (relapse prevention) studies, the NNH for anticholinergic medication use (30 to 42 [paliperidone palmitate] versus -5 to 5 [fluphenazine decanoate]), tardive dyskinesia (infinity [paliperidone palmitate]

Table 3 Key features of studies included in NNT and NNH analysis

\begin{tabular}{|c|c|c|c|c|c|c|c|}
\hline & \multirow{2}{*}{$\begin{array}{l}\text { Sample } \\
\text { size } \\
\text { (n) }\end{array}$} & \multicolumn{2}{|l|}{ Dosing } & \multicolumn{2}{|c|}{ Study duration } & \multicolumn{2}{|l|}{ Incidence of relapse } \\
\hline & & Range & $\begin{array}{l}\text { Dosing } \\
\text { interval }\end{array}$ & $\begin{array}{l}\text { Stabilization } \\
\text { period }\end{array}$ & $\begin{array}{l}\text { Double-blind } \\
\text { period }\end{array}$ & $\begin{array}{l}\text { Active treatment } \\
\text { group, n/total, (\%) }\end{array}$ & $\begin{array}{l}\text { Placebo group } \\
\text { n/total, (\%) }\end{array}$ \\
\hline \multicolumn{8}{|l|}{ Paliperidone palmitate } \\
\hline Hough et $\mathrm{al}^{16}$ & 410 & $25-100 \mathrm{mg} \mathrm{eq}$ & 4 weeks & 33 weeks & Variable range & $36 / 205$ (18\%) & $97 / 203$ (48\%) \\
\hline Pandina et al $^{17}$ & 652 & $25-150 \mathrm{mg} \mathrm{eq}^{\mathrm{b}}$ & 4 weeks & NA & 13 weeks & NA & NA \\
\hline \multicolumn{8}{|l|}{ Haloperidol decanoate } \\
\hline Eklund and Forsman ${ }^{18}$ & 56 & $60 \mathrm{mg}$ & 4 weeks & 15 weeks & 48 weeks & $2 / 20(10 \%)$ & $16 / 23(70 \%)$ \\
\hline \multicolumn{8}{|l|}{ Bromperidol decanoate } \\
\hline Smeraldi et $\mathrm{al}^{22}$ & 20 & $150 \mathrm{mg}$ & Monthly & NA & 6 months & Not mentioned & Not mentioned \\
\hline \multicolumn{8}{|l|}{ Fluphenazine decanoate } \\
\hline Hirsch et al ${ }^{19}$ & 81 & $12-25 \mathrm{mg}^{\mathrm{c}}$ & 2-4 weeks & 8 weeks & 15 months & $6 / 36(17 \%)$ & 27/38 (7I\%) \\
\hline Jolley et $\mathrm{al}^{20}$ & 54 & $\mathrm{NA}^{\mathrm{d}}$ & 4 weeks & 2 months & 48 months & $3 / 25(12 \%)$ & $12 / 24(50 \%)$ \\
\hline Odejide and Aderounmu ${ }^{21}$ & 53 & $50 \mathrm{mg}$ & 4-8 weeks & 2 years & 12 months & $5 / 21$ (19\%) & I5/27 (56\%) \\
\hline Dotti et al ${ }^{12}$ & 20 & $25-50 \mathrm{mg}$ & monthly & 6 months & 9 months & $1 / 10(10 \%)$ & $3 / 10(30 \%)$ \\
\hline (48 weeks) & & & & & & & \\
\hline
\end{tabular}

Notes: ${ }^{a}$ Doses are given monthly and ranges are expressed in terms of $\mathrm{mg}$ eq ( $234 \mathrm{mg}$ paliperidone palmitate $=150 \mathrm{mg}$ eq of paliperidone; I56 mg paliperidone palmitate $=$ $100 \mathrm{mg}$ eq of paliperidone; $78 \mathrm{mg}$ paliperidone palmitate $=50 \mathrm{mg}$ eq of paliperidone); 'lnitial dose on day I with I50 mg eq, followed by either I50, I00 or $25 \mathrm{mg}$ eq. ${ }^{\circ}$ Minimum dose $25 \mathrm{mg} / \mathrm{month}$ or $12.5 \mathrm{mg} /$ biweekly. No upper limit for dose specified; Dose range not specified. Mean dose of fluphenazine decanoate $25.6 \mathrm{mg}$. Oral haloperidol $(5-10 \mathrm{mg} / \mathrm{d})$ allowed for up to 2 weeks to treat prodromal symptoms.

Abbreviation: NA, not available (not reported in primary manuscript). 
Table 4 Number needed to treat for selected clinical outcomes

\begin{tabular}{|c|c|c|}
\hline & $\begin{array}{l}\text { Relapse prevention } \\
\text { (NNT 95\% Cl) }\end{array}$ & $\begin{array}{l}\text { Response } \\
\text { (NNT 95\% Cl) }\end{array}$ \\
\hline \multicolumn{3}{|l|}{ Paliperidone palmitate } \\
\hline $\begin{array}{l}\text { Long-term, Hough et al }{ }^{16} \\
\text { (six months) }\end{array}$ & $3(2.3,4.2)$ & NA \\
\hline $\begin{array}{l}\text { Long-term, Hough et al }{ }^{16} \\
\text { ( } 12 \text { months) }\end{array}$ & $2(1.5,2.7)$ & NA \\
\hline $\begin{array}{l}\text { Acute, Pandina et al }{ }^{17} \\
\text { (I3 weeks) }\end{array}$ & - & $6(4,10)$ \\
\hline Haloperidol decanoate & & \\
\hline $\begin{array}{l}\text { Eklund and Forsman }{ }^{18} \\
\text { (48 weeks) }\end{array}$ & $2(1.0,4.4)^{*}$ & NA \\
\hline Bromperidol decanoate & & \\
\hline Smeraldi et $\mathrm{a}^{22}$ (6 months) & NA & NA \\
\hline Fluphenazine decanoate & & \\
\hline Hirsch et al ${ }^{19}$ (nine months) & $2(1.2,3.2)^{*}$ & NA \\
\hline Jolley et $\mathrm{al}^{20}$ (two years) & $3(1.4,18.7)^{*}$ & NA \\
\hline $\begin{array}{l}\text { Odejide and Aderounmu }{ }^{21} \\
\text { (12 months) }\end{array}$ & $3(I .5,21.1)^{*}$ & NA \\
\hline Dotti et al ${ }^{12}$ (48 weeks) & $5(1.8,-6)$ & NA \\
\hline
\end{tabular}

Notes: NNT calculated relative to placebo within each study. $95 \%$ confidence intervals computed based upon Wilson scores; *Statistically significant results; response rates calculated based on $30 \%$ reduction in PANSS score. Negative bound for upper $95 \%$ confidence interval indicates a disjoint encompassing both the positive value to positive infinity, and the negative value to negative infinity.

Abbreviations: NA, not available (not reported in primary manuscript); $\mathrm{Cl}$, confidence interval; NNT, number needed to treat; PANSS, Positive and Negative Symptoms Scale.

versus 7 [fluphenazine decanoate]), and emergence of AIMS positive score ( -33 to -28 [paliperidone palmitate] versus 13 [fluphenazine decanoate]) indicated a lower incidence of treatment-emergent movement disorders with paliperidone palmitate (Table 5). A negative NNH means that a patient assigned to the comparator (placebo) has a lower risk for

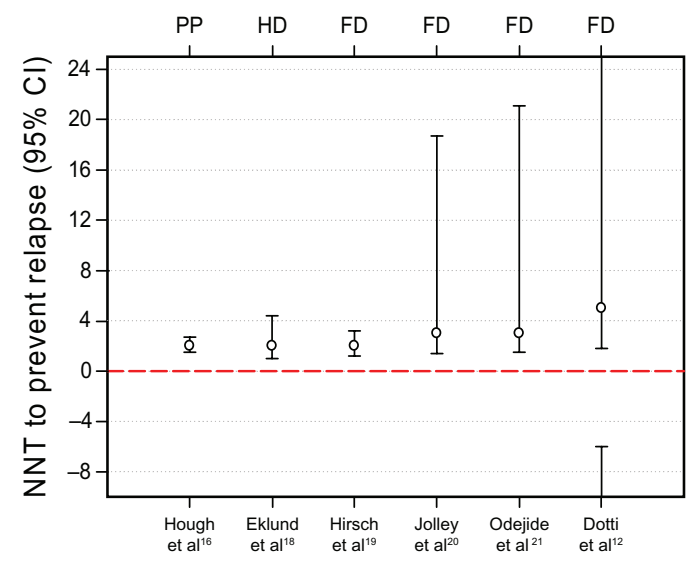

Figure I NNT point estimates and $95 \%$ confidence intervals for prevention of relapse.

Notes: Point estimate for NNT is noted with a circle. Whiskers represent upper and lower bounds of the $95 \% \mathrm{Cl}$. Disjointed $\mathrm{Cl}$ indicates that it starts from negative infinity and ends at positive infinity.

Abbreviations: $\mathrm{Cl}$, confidence interval; NNT, number needed to treat; PP, paliperidone palmitate; HD, haloperidol decanoate; FD, fluphenazine decanoate; $\mathrm{BD}$, bromperidol decanoate. the adverse event of interest than a patient assigned to the medication under study. For the comparison with haloperidol decanoate, the NNH for tardive dyskinesia favored paliperidone palmitate (infinity [paliperidone palmitate] versus 1 [haloperidol decanoate]). An infinite NNH means there is no difference in rates for the unfavorable outcome between the two interventions being compared (ie, placebo and medication of interest). However, no other relevant safety data were available to calculate a NNH for haloperidol decanoate for the other assessed parameters, ie, akathisia, tremor, anticholinergic medication, AIMS positive score, or weight gain. For the comparison with bromperidol decanoate, the NNH favored paliperidone palmitate for akathisia (205 versus 10 [bromperidol decanoate]) and tremor (69 to 207 versus -5 [bromperidol decanoate]). The $\mathrm{NNH}$ for weight gain with paliperidone palmitate ranged from 16 to 19 versus 10 (bromperidol decanoate), again favoring paliperidone palmitate. Weight gain was not reported as an adverse event in any of the haloperidol decanoate and fluphenazine decanoate studies selected. NNH results for the acute paliperidone palmitate study are provided in Table 5.

The LHH for selected parameters from maintenance studies of paliperidone palmitate or fluphenazine decanoate relative to placebo ranged between 3 and infinity across the measures of harm, and favored treatment with paliperidone palmitate (Table 6). The LHH for haloperidol decanoate and bromperidol decanoate could not be analyzed because the selected publications did not report the relevant safety or efficacy data necessary to calculate the parameters relative to placebo.

\section{Discussion}

In the absence of head-to-head comparative data from clinical studies of first- and second-generation long-acting injectable antipsychotics, calculation of NNT, NNH, and LHH across distinct studies can be useful to convey relative benefits, risks, and the ratio of benefit to risk between treatments to patients, payers, caregivers, and clinicians. ${ }^{9,30}$ One of the important benefits of using likelihood ratios is the ease of calculation and the ability to compare similar events across different studies. LHH analysis is most meaningful when LHH is compared across studies with similar objectives and design characteristics. NNT and NNH also provide clinically relevant information. Kraemer and Kupfer suggest that an NNT of 2.3, 3.6, and 8.9 corresponds to a Cohen's " $d$ " of $0.8,0.5$, and 0.2 , respectively, representing effect sizes that are "large", "medium", and "small". ${ }^{6}$ A single-digit NNT usually denotes a favorable outcome that will commonly be 
Table 5 Number needed to harm for selected clinical outcomes

\begin{tabular}{|c|c|c|c|c|c|c|}
\hline & $\begin{array}{l}\text { Akathisia } \\
\text { (NNH 95\% Cl) }\end{array}$ & $\begin{array}{l}\text { Tremor } \\
\text { (NNH 95\% Cl) }\end{array}$ & $\begin{array}{l}\text { Tardive } \\
\text { dyskinesia } \\
\text { (NNH 95\% Cl) }\end{array}$ & $\begin{array}{l}\text { Use of } \\
\text { anticholinergics } \\
\text { (NNH 95\% CI) }\end{array}$ & $\begin{array}{l}\text { AlMS } \\
\text { positive score } \\
(\mathrm{NNH} 95 \% \mathrm{Cl})\end{array}$ & $\begin{array}{l}\text { Weight gain } \\
\text { (NNH 95\% Cl) }\end{array}$ \\
\hline \multicolumn{7}{|l|}{ Paliperidone palmitate } \\
\hline $\begin{array}{l}\text { Long-term, Hough et al } \\
\text { (six months) }\end{array}$ & $205(37,-7 I)$ & $207(33,-54)$ & $\infty$ & $42(13,-35)$ & $-28(26,-9)$ & $19(11,50)$ \\
\hline $\begin{array}{l}\text { Long-term, Hough et al }{ }^{16} \\
\text { (12 months) }\end{array}$ & $205(37,-7 I)$ & $69(23,-93)$ & $\infty$ & $30(\mathrm{II},-49)$ & $-33(27,-10)$ & $16(9,40)$ \\
\hline $\begin{array}{l}\text { Acute, Pandina et al }{ }^{17} \\
\text { (13 weeks) }\end{array}$ & $-102(45,-18)$ & $-83(118,-20)$ & $\infty$ & $-90(23,-13)$ & $53(13,-19)$ & $10,004(59,-31)$ \\
\hline \multicolumn{7}{|l|}{ Haloperidol decanoate } \\
\hline $\begin{array}{l}\text { Eklund and Forsman }{ }^{18} \\
\text { (48 weeks) }\end{array}$ & NA & NA & 1 & NA & NA & NA \\
\hline \multicolumn{7}{|l|}{ Bromperidol decanoate } \\
\hline Smeraldi et al ${ }^{22}$ ( 6 months) & $10(2,-4)$ & $-5(6,-2)$ & NA & NA & NA & $10(2,-5)$ \\
\hline \multicolumn{7}{|l|}{ Fluphenazine decanoate } \\
\hline Hirsch et al ${ }^{19}$ (nine months) & NA & NA & NA & $5(3,96)$ & NA & NA \\
\hline Jolley et al ${ }^{20}$ (two years) & NA & NA & $7(-10,3)$ & NA & NA & NA \\
\hline $\begin{array}{l}\text { Odejide and Aderounmu }{ }^{21} \\
\text { ( } 12 \text { months) }\end{array}$ & NA & NA & NA & $-5(20,-2)$ & $13(4,-12)$ & NA \\
\hline Dotti et al ${ }^{12}$ (48 weeks) & NA & NA & NA & NA & NA & NA \\
\hline
\end{tabular}

Notes: NNH calculated relative to placebo within each study. $95 \%$ confidence intervals computed based upon Wilson scores; $\infty=$ confidence interval includes infinity (due to zero incidence in denominator); Negative numbers for $\mathrm{NNH}$ indicate that placebo was more likely to harm. Negative bound for upper $95 \%$ confidence interval indicates a disjoint encompassing both the positive value extending to positive infinity, and the negative value extending to negative infinity.

Abbreviations: NA, not available (not reported in primary manuscript); AIMS, Abnormal Involuntary Movement Scale; NNH, number needed to harm; Cl, confidence interval.

encountered in daily clinical practice. However, a high NNH indicates that a medication is relatively innocuous in terms of the outcome of interest, whereas a small NNH indicates that the agent is associated with a relatively higher risk of an adverse event. Thus, a long-acting injectable antipsychotic with a favorable benefit-to-risk ratio is one with a low NNT and high $\mathrm{NNH}$ relative to placebo or another long-acting injectable. ${ }^{10}$ A negative NNT means that patients may be more likely to experience a harmful outcome (relapse) by the treatment. Similarly, a negative NNH means that a favorable effect of treatment on safety parameters cannot be excluded. In addition, it should be noted that when the $95 \% \mathrm{CI}$ for either the NNT or NNH contains a negative bound, it indicates that the interval includes infinity, which implies that an infinite number of patients would be required to show any benefit, or harm, with $95 \%$ confidence, and hence denotes undetermined clinical relevance.

In the current analysis, the NNT for clinical response during acute treatment confirmed the established efficacy of paliperidone palmitate relative to placebo for the predefined

Table 6 Likelihood of being helped or harmed by paliperidone palmitate or fluphenazine decanoate relative to placebo

\begin{tabular}{|c|c|c|c|c|c|}
\hline Comparison of interest & Benefit & NNT & Harm & NNH & $\overline{\text { LHH }}$ \\
\hline $\mathrm{PPa} /$ placebo & Prevent relapse & 2.0 & Anticholinergic medication use & 30.0 & 15.1 \\
\hline $\mathrm{FD} /$ placebo & Prevent relapse & 2.0 & Anticholinergic medication use & 5.0 & 3.0 \\
\hline PPa/placebo & Prevent relapse & 2.0 & Tardive dyskinesia & $\infty$ & $\infty$ \\
\hline FDc/placebo & Prevent relapse & 3.0 & Tardive dyskinesia & 7.0 & 3.0 \\
\hline $\mathrm{PPa} /$ placebo & Prevent relapse & 2.0 & Emergent AIMS positive score & -32.2 & NA \\
\hline FD $/$ placebo & Prevent relapse & 3.0 & Emergent AIMS positive score & 13.0 & 5.0 \\
\hline $\mathrm{PPe} /$ placebo & Clinical response $e^{f}$ & 6.0 & Anticholinergic medication use & -89.3 & NA \\
\hline $\mathrm{PPe} /$ placebo & Clinical response $\mathrm{e}^{f}$ & 6.0 & Emergent AIMS positive score & 52.2 & 10.0 \\
\hline $\mathrm{PPe} /$ placebo & Clinical response $\mathrm{e}^{f}$ & 6.0 & Emergent extrapyramidal symptoms & 488.0 & 89.0 \\
\hline
\end{tabular}

Notes: NNT and NNH calculated relative to placebo, eg, [I/(\% LAI - \% placebo)]. LHH calculated as [NNH/NNT]. Negative NNT indicates that the placebo was more beneficial than the LAI. Positive NNT indicates that the LAI was more beneficial than the placebo. Negative NNH indicates that the placebo was more harmful than the LAI.

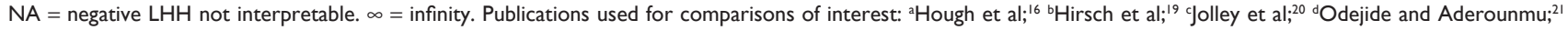
ePandina et al; ${ }^{17}$ fClinical response (PANSS improvement ( $\geq 30 \%$ ).

Abbreviations: PANSS, Positive and Negative Symptoms Scale, NNT, number needed to treat; NNH, number needed to harm; AlMS, Abnormal Involuntary Movement Scale; LAl, long-acting injectable. 
primary efficacy measure. This result is to be interpreted with caution, considering that the search criteria retrieved only one relevant study for paliperidone palmitate that evaluated the product's efficacy and safety for acute treatment of patients with schizophrenia and no studies for any of the first-generation long-acting injectables. The NNTs to prevent relapse relative to placebo were similar between paliperidone palmitate, fluphenazine decanoate, and haloperidol decanoate, while no relevant efficacy data were available for bromperidol decanoate. Overall, the NNH favored paliperidone palmitate over fluphenazine decanoate for the assessed safety measures. As a result, the paired calculations of LHH for benefit with regard to relapse, as well as risk for each of the distinct measures of harm, also favored paliperidone palmitate over fluphenazine decanoate. Similarly, the NNHs as measures of harm for anticholinergic medication use, onset of tardive dyskinesia, and emergent AIMS positive score, favored paliperidone palmitate over fluphenazine decanoate. Because we did not obtain efficacy data to calculate NNT for relapse prevention during maintenance treatment, or data to calculate $\mathrm{NNH}$ for all the selected safety parameters for the first-generation antipsychotic long-acting injectables evaluated, a comparison of LHH between paliperidone palmitate and bromperidol decanoate or haloperidol decanoate was not possible.

Many of the previous reports comparing first- and second-generation antipsychotics only compared the oral formulations. ${ }^{31-33}$ Similar comparative data on first- versus second-generation long-acting injectables, especially data from head-to-head comparisons, which can provide the strongest evidence, are lacking. However, our findings are consistent with a previous meta-analysis for NNT and NNH that showed fewer extrapyramidal side effects with secondgeneration oral antipsychotics than their first-generation oral antipsychotics. ${ }^{34}$ Thus, the results from these analyses provide important information, especially for the comparison of specific extrapyramidal symptom-related adverse events and tardive dyskinesia between the newly approved longacting injectable, paliperidone palmitate, and the selected first-generation long-acting injectables.

The favorable results from LHH analyses for paliperidone palmitate are especially important, because tardive dyskinesia is one of the main adverse effects of concern with the use of first-generation antipsychotics in the treatment of schizophrenia. ${ }^{5}$ The prevalence of tardive dyskinesia has been estimated to be between $24 \%-56 \%$ in chronic antipsychotic users, ${ }^{35}$ $13 \%-36 \%$ in hospitalized adult patients, ${ }^{36}$ and $25 \%-30 \%$ among elderly patients treated with first-generation oral antipsychotics. ${ }^{4}$ Several studies have consistently reported a higher risk of treatment-limiting tardive dyskinesia with the first-generation oral antipsychotics than with the secondgeneration oral antipsychotics. ${ }^{4,5,37}$ Consistent with these reports for oral formulations, a recent comparative review suggests that first-generation long-acting injectables are also associated with an increased incidence of acute and chronic movement disorders compared with the second-generation long-acting injectable, risperidone..$^{38}$ In recently published paliperidone palmitate trials, there were no reports of tardive dyskinesia in the short-term trials $(\mathrm{n}=1805),{ }^{17,23-25}$ and only one report in the longer-term trials $(\mathrm{n}=1010){ }^{16,39,40}$

However, second-generation oral antipsychotics are generally considered to be associated with an increased incidence of metabolic adverse events and weight gain. ${ }^{41-43}$ Metabolic adverse events for the selected first-generation long-acting injectables and paliperidone palmitate could not be compared in this analysis due to lack of adequate data from the selected firstgeneration long-acting injectable studies. However, weight gain in long-term treatment, reported as an adverse event, could be compared, and favored paliperidone palmitate over bromperidol decanoate (NNH 16-19 for paliperidone palmitate versus 10 for bromperidol decanoate). Previous short-term paliperidone palmitate studies ${ }^{23-25}$ (up to 13 weeks), a recent long-term paliperidone palmitate study, ${ }^{39}$ and a recent comparative review that included paliperidone palmitate studies up to one year in duration ${ }^{44}$ report low mean changes from baseline in body weight $(-1.0 \mathrm{~kg}$ to $2.6 \mathrm{~kg})$. For body weight increases from baseline of at least $7 \%$ versus placebo, an $\mathrm{NNH}$ of 12 and 13 for paliperidone palmitate studies was reported. ${ }^{44}$

Limitations of the current analysis include lack of more current data on first-generation long-acting injectables to compare with paliperidone palmitate, incomplete data reported in the selected studies for comparison, lack of data on other second-generation long-acting injectables (eg, risperidone), differences in study design among the selected studies (eg, immediate randomization to distinct treatment groups or randomized withdrawal after initial stabilization), different definitions of relapse, small sample size of older studies, variable length of follow-up, and different proportions of patients pretreated with medications to minimize adverse events (eg, anti-extrapyramidal symptom medication). At the time of this analysis, long-acting injectable risperidone was also considered for comparison, but was later excluded because the relevant studies did not meet the inclusion criteria for the analysis. Furthermore, because of the lack of any published studies with conventional longacting injectables in the acute setting, it was not possible to 
compare NNT for treatment response. NNT or NNH is not "an all-inclusive measure of benefit or harm", but provides clinicians with a means of weighing benefits versus risks of the medications in the class when determining the most appropriate course of treatment for an individual patient. While it is difficult to interpret a potential net benefit or harm based on multiple NNTs or NNHs for individual parameters, this method constitutes a valuable addition to the decisionmaking tool kit for patient care. Thus, availability of NNTs or NNHs for various efficacy and safety parameters may facilitate more individualized decision-making in the management of patients with distinct baseline characteristics.

Because the risks and benefits documented on the basis of aggregate clinical trial data vary between the antipsychotic long-acting injectables, it is important for prescribers to individualize treatment decisions based upon the balance of opposing benefits and risks for their patients with a distinct clinical presentation and a specific set of risk factors. In the present analysis, paliperidone palmitate was generally found to have a similar NNT and a more favorable NNH compared with selected first-generation long-acting injectables for maintenance treatment in patients with schizophrenia.

\section{Acknowledgment}

Dr Balasubramanian Ramanathan (SIRO Clinpharm Pvt. Ltd) provided writing assistance and Dr Wendy P. Battisti (Johnson \& Johnson Research \& Development, LLC) provided additional editorial support. The authors would like to acknowledge Dr Cristiana Gassmann-Mayer (Johnson \& Johnson Research \& Development, LLC) for reviewing the Italian manuscript included in this research.

\section{Disclosures}

This study was funded by Johnson \& Johnson Pharmaceutical Research \& Development, LLC, Raritan, NJ, USA. The sponsor also provided a formal review of the manuscript. Drs Gopal, Berwaerts, Nuamah, Coppola, Daly, Hough and Palumbo are employees of Johnson \& Johnson Pharmaceutical Research \& Development LLC; Dr Akhras was an employee of Johnson \& Johnson Pharmaceutical Services, Raritan, NJ, USA at the time of this study and is currently an employee of Pfizer Inc. All authors met ICMJE criteria and all those who fulfilled those criteria are listed as authors. All authors had access to the study data and made the final decision about where to publish these data and approved submission to this journal. Data from this study were presented at the American Society for Experimental
NeuroTherapeutics 12th annual meeting, Bethesda, MD, March 4-6, 2010, at the Society of Biological Psychiatry 65th annual meeting, May 20-22, New Orleans, LA, 2010, and International College of Neuropsychopharmacology World Congress, Hong Kong, June 6-10, 2010.

Registration: The paliperidone palmitate trials included in this analysis are registered in ClinicalTrials.Gov (Hough et al., 2010 [NCT00111189], Pandina et al., 2010 [NCT00590577]). Those trials with the first generation antipsychotics included in this analysis were conducted before registration was required.

\section{References}

1. Nayak RK, Doose DR, Nair NP. The bioavailability and pharmacokinetics of oral and depot intramuscular haloperidol in schizophrenic patients. J Clin Pharmacol. 1987;27(2):144-150.

2. Olivares JM, Rodriguez-Morales A, Diels J, et al. Long-term outcomes in patients with schizophrenia treated with risperidone long-acting injection or oral antipsychotics in Spain: Results from the electronic Schizophrenia Treatment Adherence Registry (e-STAR). Eur Psychiatry. 2009;24(5):287-296.

3. Bransgrove LL, Kelly MW. Movement disorders in patients treated with long-acting injectable antipsychotic drugs. Am J Hosp Pharm. 1994;51(7):895-899.

4. Correll CU, Leucht S, Kane JM. Lower risk for tardive dyskinesia associated with second-generation antipsychotics: A systematic review of 1-year studies. Am J Psychiatry. 2004;161(3):414-425.

5. Gharabawi GM, Bossie CA, Zhu Y, et al. An assessment of emergent tardive dyskinesia and existing dyskinesia in patients receiving longacting, injectable risperidone: Results from a long-term study. Schizophr Res. 2005;77(2-3):129-139.

6. Kraemer HC, Kupfer DJ. Size of treatment effects and their importance to clinical research and practice. Biol Psychiatry. 2006;59(11):990-996.

7. Citrome L, Kantrowitz J. Antipsychotics for the treatment of schizophrenia: Likelihood to be helped or harmed, understanding proximal and distal benefits and risks. Expert Rev Neurother. 2008;8(7):1079-1091.

8. Citrome L. Compelling or irrelevant? Using number needed to treat can help decide. Acta Psychiatr Scand. 2008;117(6):412-429.

9. Straus SE. Individualizing treatment decisions. The likelihood of being helped or harmed. Eval Health Prof. 2002;25(2):210-224.

10. Citrome L. Show me the evidence: Using number needed to treat. South Med J. 2007;100(9):881-884.

11. Martinez-Aran A, Vieta E, Chengappa KN, Gershon S, Mullen J, Paulsson B. Reporting outcomes in clinical trials for bipolar disorder: A commentary and suggestions for change. Bipolar Disord. 2008;10(5): 566-579.

12. Dotti A, Bersani G, Rubino IA, Elliseo C. Double blind trial of fluphenazine decanoate against placebo in ambulant maintenance treatment of chronic schizophrenics. Rivista di Psichiatria. 1979;14(5):374-383.

13. David A, Adams CE, Eisenbruch M, et al. Depot fluphenazine decanoate and enanthate for schizophrenia. Cochrane Database Syst Rev. 2005;1: CD000307.

14. Adams CE, David A, Quraishi SN. Depot bromperidol decanoate for schizophrenia. Cochrane Database Syst Rev. 2004;3:CD001719.

15. Quraishi SN, David A, Brasil MA, Alheira FV. Depot haloperidol decanoate for schizophrenia. Cochrane Database Syst Rev. 1999;1: CD001361.

16. Hough D, Gopal S, Vijapurkar U, Lim P, Morozova M, Eerdekens M. Paliperidone palmitate maintenance treatment in delaying the time-to-relapse in patients with schizophrenia: A randomized, double-blind, placebocontrolled study. Schizophr Res. 2010;116(2-3):107-117. 
17. Pandina G, Lindenmayer J-P, Lull J, et al. Randomized, placebo-controlled study to assess the efficacy and safety of three doses of paliperidone palmitate in adults with acutely exacerbated schizophrenia. J Clin Psychopharmacol. 2010;30(3):235-244.

18. Eklund K, Forsman A. Minimal effective dose and relapse-doubleblind trial: Haloperidol decanoate vs. placebo. Clin Neuropharmacol. 1991;14(Supp1 2):S7-S12.

19. Hirsch SR, Gaind R, Rohde PD, Stevens BC, Wing JK. Outpatient maintenance of chronic schizophrenic patients with long-acting fluphenazine: Double-blind placebo trial. Report to the Medical Research Council committee on clinical trials in psychiatry. BMJ. 1973;1(5854): 633-637.

20. Jolley AG, Hirsch SR, Morrison E, McRink A, Wilson L. Trial of brief intermittent neuroleptic prophylaxis for selected schizophrenic outpatients: Clinical and social outcome at two years. BMJ. 1990; 301(6756):837-842.

21. Odejide OA, Aderounmu AF. Double-blind placebo substitution: Withdrawal of fluphenazine decanoate in schizophrenic patients. J Clin Psychiatry. 1982;43(5):195-196.

22. Smeraldi EB, Bellini L, Rochi P, Volonte MV, Virzi A, Aguglia E. Bromperidol decanoate versus placebo in treating schizophrenia in the residual phase. New Trends Exp Clin Psychiatry. 1990;6:187-198.

23. Kramer M, Litman R, Hough D, et al. Paliperidone palmitate, a potential long-acting treatment for patients with schizophrenia. Results of a randomized, double-blind, placebo-controlled efficacy and safety study. Int J Neuropsychopharmacol. 2010;13(5):635-647.

24. Nasrallah HA, Gopal S, Gassmann-Mayer C, et al. A controlled, evidencebased trial of paliperidone palmitate, an investigational long-acting injectable antipsychotic in schizophrenia. Neuropsychopharmacology. 2010;35(10):2072-2082.

25. Gopal S, Hough D, Xu H, et al. Efficacy and safety of paliperidone palmitate in adult patients with acutely symptomatic schizophrenia: A randomized, double-blind, placebo-controlled, dose-response study. Int Clin Psychopharmacol. 2010;25(5):245-256.

26. Altman DG, Andersen PK. Calculating the number needed to treat for trials where the outcome is time to an event. BMJ. 1999;319(7223): 1492-1495.

27. Bender R. Calculating confidence intervals for the number needed to treat. Control Clin Trials. 2001;22(2):102-110.

28. Newcombe RG. Interval estimation for the difference between independent proportions: Comparison of eleven methods. Stat Med. 1998;17(8): 873-890.

29. Wilson EB. Probable inference, the law of succession, and statistical inference. J Am Stat Assoc. 1927;22(158):209-212.

30. Schlectman E. Odds ratio, relative risk, absolute risk reduction, and the number needed to treat - which of these should we use? Value Health. 2002;5(5):431-436.
31. Citrome L, Stroup TS. Schizophrenia, Clinical Antipsychotic Trials of Intervention Effectiveness (CATIE) and number needed to treat: How can CATIE inform clinicians? Int J Clin Pract. 2006;60(8):933-940.

32. Karagianis J, Rosenbluth M, Tohen M, et al. Reviewing CATIE for clinicians: Balancing benefit and risk using evidence-based medicine tools. Curr Med Res Opin. 2007;23(10):2551-2557.

33. Stauffer V, Karagianis J, Sutton V, et al. Number needed to treat (NNT) and number needed to harm $(\mathrm{NNH})$ in randomized, blinded trials comparing olanzapine to other atypical antipsychotics for treatment of schizophrenia. Clin Schizophr Relat Psychoses. 2008;2(2):136-146.

34. Leucht S, Corves C, Arbter D, Engel RR, Li C, John M. Secondgeneration versus first-generation antipsychotic drugs for schizophrenia: A meta-analysis. Lancet. 2009;373(657):31-41.

35. Tepper SJ, Haas JF. Prevalence of tardive dyskinesia. J Clin Psychiatry. 1979;40(12):508-516.

36. Kane JM. Tardive dyskinesisa rate with atypical antipsychotics in adults: Prevalence and incidence. J Clin Psychiatry. 2004;65(Supp1 9): 16-20.

37. Correll CU, Schenk EM. Tardive dyskinesia and new antipsychotics. Curr Opin Psychiatry. 2008;21(2):151-156.

38. Taylor D. Psychopharmacology and adverse effects of antipsychotic long-acting injections: A review. Br J Psychiatry Suppl. 2009;195: S13-S19.

39. Coppola D, Liu Y, Gopal S, et al. Long-term safety, tolerability and pharmacokinetics of highest available dose of paliperidone palmitate: A one-year open-label study in patients with schizophrenia (submitted).

40. Gopal S, Vijapurkar U, Lim P, Morozova M, Eerdekens M, Hough D. A 52-week open-label study of the safety and tolerability of paliperidone palmitate in patients with schizophrenia. J Psychopharmacol. July 8, 2010. [Epub ahead of print].

41. De Hert M, Schreurs V, Sweers K, et al. Typical and atypical antipsychotics differentially affect long-term incidence rates of the metabolic syndrome in first-episode patients with schizophrenia: A retrospective chart review. Schizophr Res. 2008;101(1-3):295-303.

42. Lee E, Chow LY, Leung CM. Metabolic profile of first and second generation antipsychotics among Chinese patients. Psychiatry Res. 2011;185(3):456-458.

43. Tarricone I, Casoria M, Gozzi BF, et al. Metabolic risk factor profile associated with use of second generation antipsychotics: A cross sectional study in a community mental health centre. BMC Psychiatry. 2006;6:11.

44. Citrome L. Paliperidone palmitate - review of the efficacy, safety and cost of a new second-generation depot antipsychotic medication. Int J Clin Pract. 2010(2):216-239.
Neuropsychiatric Disease and Treatment

\section{Publish your work in this journal}

Neuropsychiatric Disease and Treatment is an international, peerreviewed journal of clinical therapeutics and pharmacology focusing on concise rapid reporting of clinical or pre-clinical studies on a range of neuropsychiatric and neurological disorders. This journal is indexed on PubMed Central, the 'PsycINFO' database and CAS, and is the official

\section{Dovepress}

journal of The International Neuropsychiatric Association (INA). The manuscript management system is completely online and includes a very quick and fair peer-review system, which is all easy to use. Visit http://www.dovepress.com/testimonials.php to read real quotes from published authors. 